\title{
Acid-base Abnormalities in Infants with Congenital Heart Disease
}

\author{
V. R. KAMATH,*† M.B., B.S., M.R.C.P.ED. ; R. S. JONES,* M.D., M.R.C.P., D.C.H.
}

Brit. med. F., 1966, 2, 434-436

Information about the frequency, nature, and extent of acidbase abnormalities in infants with congenital heart disease is limited. Gootman et al. (1963) reported four cases with Fallot's tetralogy, pulmonary atresia, transposition of the great vessels, and severe pulmonary stenosis. All were cyanosed at the time of investigation and had a low $p \mathrm{H}(7.05-7.28)$ due to base depletion. Rudolph and Danilowicz (1963) reported the case of a $10 \frac{1}{2}$-month-old infant with pulmonary atresia and ventricular septal defect in a severe cyanotic attack with an arterial $\mathrm{pH}$ of 7.08 . Conventional treatment did not produce any improvement, whereas an infusion of sodium bicarbonate brought about dramatic improvement in the level of consciousness and the $p \mathrm{H}$ rose to 7.38. Talner et al. (1965) reported 20 infants with congenital heart disease in cardiac failure with increased pulmonary blood-flow and/or pulmonary venous hypertension. They demonstrated the existence of raised arterial $\mathrm{PCO}_{2}$ levels in those with failure. Sunico et al. (1960) had previously reported similar findings.

In this paper the acid-base abnormalities in a group of 85 infants with congenital heart disease are examined and correlated with the clinical state. The therapeutic implications are discussed.

\section{Methods}

The infants were examined during admission for investigation or treatment. They were assessed clinically with a view to determining the type of congenital abnormality, the presence or absence of cyanosis, cardiac failure, and respiratory infection. They were also investigated by cardiac catheterization and cardio-angiography when indicated.

The acid-base state was examined by collecting capillary samples by the technique previously described by Jones et al. (1964), and were subsequently analysed by the interpolation method (Siggaard Andersen et al., 1960). The base deficit was calculated from a nomogram and corrections were made with the method described by these authors. Small differences between the values obtained from capillary and arterial blood occur, especially when the $p H$ is in the region of 7 , but we are satisfied that the correlation was close enough for our purposes (Jones et al., 1964). The $\mathrm{PCO}_{2}$ values have not been corrected for arterial unsaturation, so that the results reported here cannot be compared with those of Talner et al. (1965).

Results were analysed, Yates's modification of the $\chi^{2}$ test (Yates, 1953) and Student's t-test being used.

\section{Results}

There are two sets of circumstances which give rise to acidbase abnormalities in infants. First, there are the abnormalities found in acute cardio-respiratory failure-that is, states of collapse. These are always associated with a gross base depletion, a $p \mathrm{H}$ in the region of 7 , and, if respiratory failure has been a prominent feature, a high $\mathrm{PCO}_{2}$ level. Secondly, there are the abnormalities found in infants at rest in a stable or relatively stable state. They may have cyanotic or acyanotic

* From the Cardiac Unit; the Royal Liverpool Children's Hospital.

+ Now at Circulation Laboratory, Tufts University School of Medicine, Boston City Hospital, Boston, Mass. congenital heart disease, they may or may not have respiratory infections, and may or may not have congestive cardiac failure. The observations reported here are confined to the second group, so that they were made only during periods when the infants were in a stable state and when the effects of operations, investigations, assisted ventilation, and intravenous therapy were regarded as unlikely to have affected the result. Diagnosis of failure was made in the presence of liver enlargement $2.5 \mathrm{~cm}$. below the costal margin with or without peripheral oedema. These infants were as a rule apyrexial. Infection was diagnosed in the presence of pyrexia, widespread rales, especially when asymmetrical, and radiological evidence of consolidation. The clinical material is summarized in Tables I and II.

Values for standard bicarbonate, $p \mathrm{H}$, and $\mathrm{PCO}_{2}$ for the group as a whole are shown in Table III. The $\mathrm{PCO}_{2}$ levels are not significantly different in the cyanotic and acyanotic groups. The $\mathrm{pH}$ is significantly lower in the cyanotic group owing to base depletion.

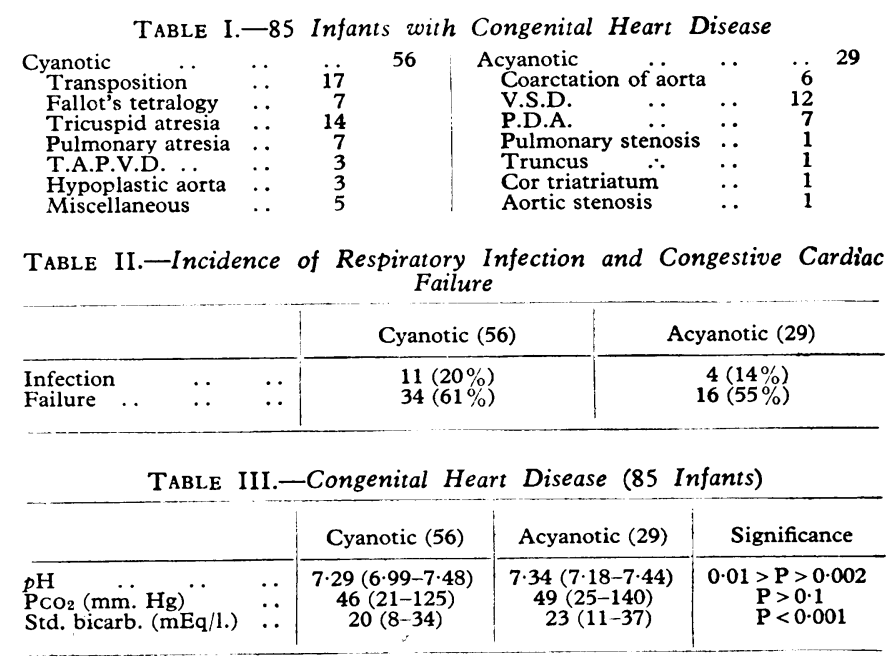

Cyanosis.-In order to define the effect of cyanosis, all those with infection and cardiac failure were excluded. Observations on the remainder are shown in Table IV, where they are divided into cyanotic and acyanotic groups. The $\mathrm{PCO}_{2}$ is not significantly different in the two groups. The $p \mathrm{H}$ is lower in the cyanotic group because of depletion of base, the standard

TABLE IV.-30 Infants Without Failure or Infection

\begin{tabular}{|c|c|c|c|c|}
\hline & & Cyanotic (21) & Acyanotic (9) & Significance \\
\hline $\begin{array}{l}\mathrm{pH} \quad \ldots . \\
\mathrm{PCO}_{2}(\mathrm{~mm} . \mathrm{Hg}) \\
\text { Std. bicarb. (mEq/1.) }\end{array}$ & $\begin{array}{l}\ldots \\
\cdots\end{array}$ & \begin{tabular}{|c|}
$7 \cdot 30(7 \cdot 11-7 \cdot 41)$ \\
$39(23-77)$ \\
$18(10-23)$
\end{tabular} & $\begin{array}{c}7 \cdot 36(7 \cdot 28-7 \cdot 44) \\
46(35-57) \\
24(21-28)\end{array}$ & $\begin{array}{l}P=0.02 \\
P>0.1 \\
P<0.001\end{array}$ \\
\hline
\end{tabular}

bicarbonate being significantly lower in this group. Of the 21 in the cyanotic group seventeen have values for standard bicarbonate which are below normal, whereas all nine in the acyanotic group have values above the lower limit of the normal range.

Infection.-Since only four in the acyanotic group had respiratory infections, the following observations are confined to the cyanotic group (Table V). As expected, the $\mathrm{PcO}_{2}$ is significantly higher in the group with infection. Nine of the 
11 had values for $\mathrm{PCO}_{2}$ above normal, whereas 36 of the 45 without infection had values within normal limits. The standard bicarbonate is significantly higher in the group with infection. In fact 7 of the 11 in this group had values above normal and only three were below the normal range. Of the 45 without infection 32 were below normal and only two above normal. Infections in these infants tend to be of low grade and rather chronic, doubtless accounting for the high bicarbonate figures in this group.

\begin{tabular}{|c|c|c|c|c|}
\hline & & Infection (11) & No Infection (45) & Significance \\
\hline $\begin{array}{l}\mathrm{pH} \quad . . \mathrm{Hg}) \\
\mathrm{PCO}_{2}(\mathrm{~mm} . \mathrm{Hg} \\
\text { Std. bicarb. (mEq!1.) }\end{array}$ & $\begin{array}{l}\cdots \\
\cdots\end{array}$ & $\begin{array}{c}7 \cdot 28(7 \cdot 10-7 \cdot 41) \\
72(32-125) \\
25(18-34)\end{array}$ & $\begin{array}{c}7 \cdot 29(6 \cdot 99-7 \cdot 48) \\
39(21-86) \\
19(8-31)\end{array}$ & $\begin{array}{c}P>0.1 \\
0.01>P>0.002 \\
P=0.002\end{array}$ \\
\hline
\end{tabular}

Failure.-Table VI shows the effects of failure in the cyanotic and acyanotic groups after exclusion of those with evidence of respiratory infection. It can be seen that the mean values are similar in all instances, and the differences in $p \mathrm{H}, \mathrm{PCO}_{2}$, and standard bicarbonate between those with and without failure are not significant.

\begin{tabular}{|c|c|c|c|c|}
\hline & & Failure & No Failure & Significance \\
\hline \multicolumn{5}{|c|}{ Cyanotic Group Without Infection (45 Infants) } \\
\hline 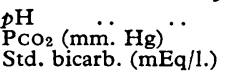 & $\begin{array}{l}. . \\
\cdots\end{array}$ & $\begin{array}{c}7 \cdot 28(6 \cdot 99-7 \cdot 48) \\
41(21-86) \\
19(8-31)\end{array}$ & $\begin{array}{c}7 \cdot 30(7 \cdot 11-7 \cdot 41) \\
39(23-77) \\
18(10-23)\end{array}$ & $\begin{array}{l}P>0.1 \\
P>0.1 \\
P>0.1\end{array}$ \\
\hline \multicolumn{5}{|c|}{ Acyanotic Group Without Infection (25 Infants) } \\
\hline $\begin{array}{l}\mathrm{pH} \quad . . \\
\mathrm{PCO}_{2}(\mathrm{~mm} . \mathrm{Hg})\end{array}$ & $\because$ & $\begin{array}{c}7 \cdot 35(7 \cdot 18-7 \cdot 44) \\
41(25-63) \\
22(11-29)\end{array}$ & $\mid \begin{array}{c}7 \cdot 36(7 \cdot 28-7 \cdot 44) \\
46(35-57) \\
24(21-28)\end{array}$ & $\begin{array}{l}P>0.1 \\
P>0.1 \\
P>0.1\end{array}$ \\
\hline
\end{tabular}

Relation Between Failure and Infection in the Cyanotic Group.-Of the 56 with cyanosis $34(61 \%)$ were in congestive cardiac failure (Table VII). The incidence of failure in those with infection is significantly higher than in those without, which supports the clinical impression that respiratory infection is commonly associated with failure in these infants.

TABLE VII.-Cyanotic Group (56 Infants)

\begin{tabular}{|c|c|c|c|c|c|}
\hline & & & Infection & No Infection & Total \\
\hline $\begin{array}{l}\text { No failure } \\
\text { Failure .. }\end{array}$ & $\therefore$ & $\therefore$ & $\begin{array}{c}1(9 \%) \\
10(91 \%)\end{array}$ & $\begin{array}{l}21(47 \%) \\
24(53 \%)\end{array}$ & $\begin{array}{l}22(39 \%) \\
34(61 \%)\end{array}$ \\
\hline Total & $\ldots$ & $\ldots$ & 11 & 45 & 56 \\
\hline
\end{tabular}

\section{Significance of Abnormalities}

The abnormalities which have to be considered are: (1) metabolic acidosis in cyanotic congenital heart disease, (2) respiratory acidosis in cyanotic and acyanotic congenital heart disease with respiratory infection, and (3) metabolic acidosis with or without respiratory acidosis of acute onsetacute cardio-respiratory failure (states of collapse).

The significance of acid-base abnormalities turns largely upon the importance of $\mathrm{pH}$ in the arterial blood in relation to its effect upon cardiac function. The response of the myocardium to sympatho-adrenal stimulation has an important bearing upon cardiac output. Hypotensive states and hypercarbia increase activity of this system with liberation of catecholamines (Poole and Watts, 1959 ; Walton et al., 1959). Catecholamines increase anaerobic glycolysis with liberation of lactic acid (Lundholm, 1956). The amines greatly increase the contractile force of the ventricle. It has been shown experimentally that the ventricle becomes refractory to the amines when the $p \mathrm{H}$ is low (less than 7.1) (Thrower et al., 1961). The depressant effect of acidaemia upon the myocardium is masked at first by stimulation of the sympatho-adrenal system, but finally prevails, and cardiovascular failure occurs in the presence of high plasma catecholamine levels. There is evidence that this refractoriness is due to the accumulation of end-products of anaerobic metabolism at the site of formation in the tissues, and this decreases the rate of energy release (Darby et al., 1960). Gerst et al. (1964) have shown in experimental animals that the ventricular fibrillation threshold decreases in the presence of acidaemia, indicating a greater susceptibility to ventricular fibrillation. Stewart et al. (1962) and Stewart (1964) have produced convincing evidence for the profound effect of low $p H$ levels on myocardial function and have stressed the implications in the treatment of cardiac arrest.

In the group of infants we studied it was our experience that it was impossible to establish a satisfactory cardiac output once a low output state had occurred, until the $p \mathrm{H}$ had been raised to at least 7.2 by giving sodium bicarbonate intravenously when there was evidence of base depletion and by assisted ventilation when there was evidence of respiratory failure.

\section{Metabolic Acidosis}

It is well established that hypoxic states are associated with a low arterial $\mathrm{pH}$ level due to base depletion. Huckabee (1958) has shown that anaerobic tissue metabolism begins to assume a significant role at low $\mathrm{PO}_{2}$ levels because of the excessive production of lactic acid. Presumably renal compensation for this mechanism becomes inadequate. It was therefore of interest to find evidence of a compensatory alkalosis in the cyanotic group with infection. The $p \mathrm{H}$ was not lower in this group than in the group without infection, owing to high bicarbonate levels compensating for elevation of $\mathrm{PCO}_{2}$.

The demonstration of a base deficit is not necessarily an indication to treat it. It should be treated only if the actual $p \mathrm{H}$ is less than 7.2 , and this can be done by giving oral sodium bicarbonate $(2.74 \%)$, or, if there is urgency, intravenous sodium bicarbonate $(2.74 \%$ or $5 \%)$. Caution is necessary in the presence of impaired renal function, when the deficit should be corrected incompletely and slowly, otherwise convulsions are apt to occur. The dosage is that which is necessary to repair the deficit. The formula suggested by Astrup is a useful guide. ${ }^{1}$

There are certain circumstances in which full correction of base deficit is advisable, whenever possible in advance, as a prophylactic measure. These are circumstances which are apt to accentuate the hypoxia and acidaemia already present: (1) when cyanotic attacks are occurring; (2) at the onset of acute respiratory infections; (3) prior to catheterization and cardioangiography; (4) prior to operation; and (5) when there is a progressive acidaemia in severe lesions.

Cyanotic attacks produce depletion of base, which may become serious if attacks occur frequently. An important part of their treatment should be careful control of the acid-base state in order to prevent cardiorespiratory failure supervening.

Respiratory infection is apt to produce $\mathrm{CO}_{2}$ retention, which depresses $p \mathrm{H}$. The repair of a base deficit becomes important in addition to treatment directed towards the lowering of a raised $\mathrm{PCO}_{2}$ level.

Operations, cardiac or non-cardiac, and even relatively minor procedures such as cardiac catheterization, are apt to depress cardiac and/or respiratory function. Since these functions may already be barely adequate for metabolic needs, the additional effect of a low $p \mathrm{H}$ should be removed and the acid-base state carefully controlled from the outset.

Severe cyanotic lesions in the terminal stages of the disease develop a progressive and largely uncontrollable metabolic acidosis. That is to say, response to the usual doses of bicarbonate is transient and base depletion recurs within a few hours. There is no point in attempting to maintain a normal acid-base ${ }^{1} \mathrm{mEq}$ of sodium bicarbonate $=$ base excess in $\mathrm{mEq} / \mathrm{l}$. (determined from
nomogram) $\times$ body-weight in $\mathrm{kg} . \times 0.3$. 
status by giving alkali in these circumstances, unless it is with the object of carrying out some procedure such as a corrective operation. This type of abnormality is satisfactorily controllable only with the aid of a partial perfusion technique which incorporates dialysing and oxygenating units.

In addition to correction of the metabolic abnormality, it is important to avoid factors which will aggravate the situation. These are: (1) episodes of hypoventilation-for example, during anaesthesia and due to excessive sedation; (2) hypovolaemia due to blood loss; and (3) factors which lower cardiac output.

Hypoventilation.-Efficient anaesthesia, which will avoid abnormal $\mathrm{PO}_{2}$ and $\mathrm{PCO}_{2}$ levels due to inadequate ventilation, is essential for cardiac and non-cardiac operations. In the severely ill infant procedures such as cardiac catheterization may be best carried out under anaesthesia with assisted ventilation and a relaxant, thus avoiding sedation, which might depress respiration.

Hypovolaemia.-Any loss of blood at catheterization or operation should be corrected without delay. If losses are appreciable the aim should be to maintain a normal venouspressure level in the right atrium rather than attempt to replace estimated losses.

Cardiac Output.-Factors which may lower cardiac output should be avoided-for example, calcium-potassium imbalance due to citrated blood should be corrected by appropriate quantities of calcium ; excessive handling of the heart during surgery should be avoided so far as is possible in non-perfusion operations ; prolonged coronary occlusions should be avoided.

\section{Respiratory Infection}

Relatively minor respiratory infections require vigorous treatment on account of their tendency to produce respiratory and cardiac failure. The majority respond to antibiotics, oxygen, and humidity. Progressive respiratory failure is frequently due to accumulation of secretions in the airway, and this obstructive factor is often more important than extension of a pneumonic process in the lung. When the usual measures fail a nasal endotracheal plastic tube is passed (Fig. 1) and bronchial aspira-

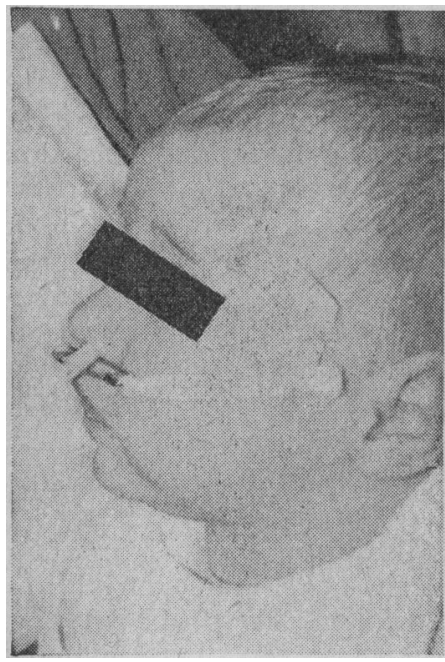

FIG. 1

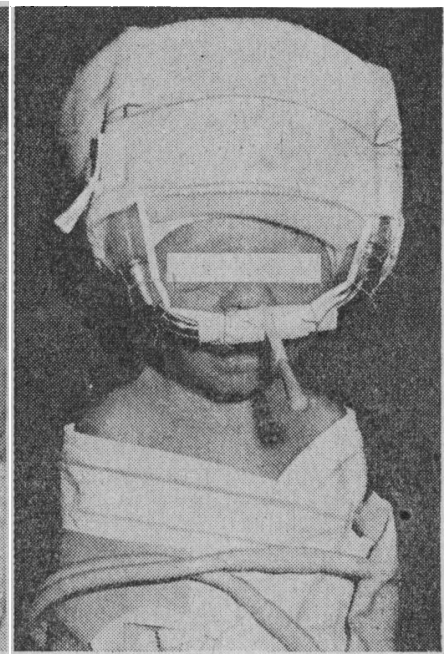

FIG. 2
Fig. 1.-Showing passage of the nasal endotracheal plastic tube. Fig. 2. -The Jackson Rees plastic tube in position.

tion is carried out via this with a small sterile rubber catheter. Should respiratory failure progress despite these measures, this tube is exchanged for the Jackson Rees plastic tube ${ }^{2}$ shown in Fig. 2. The lateral limbs are coupled to a ventilator. The specially designed head harness affords rigid support for the

Made by Portex Plastics. tube. The fourth limb is normally closed with a spigot, which is removed from time to time in order to carry out bronchial aspiration with a sterile catheter. The action of the ventilator is not interfered with in any way by the nurse during this procedure.

\section{Acute Cardio-respiratory Failure}

The importance of correcting acid-base abnormalities after an episode of acute cardio-respiratory failure has been stressed in the past (Stewart et al., 1962 ; Milstein, 1963 ; Stewart, 1964), and the principles of treatment apply equally to infants with congenital heart disease. We'would stress that the timing of therapeutic measures is all-important. Immediately after beginning assisted ventilation and external cardiac massage (whether actual cardiac arrest has occurred or not) a solution of 2.74 sodium bicarbonate should be injected into a scalp vein in a dose of $5 \mathrm{ml} . / \mathrm{kg}$. body-weight. The acid-base status is subsequently measured and further treatment given in accordance with the results.

\section{Summary}

Acid-base abnormalities in a group of 85 infants with congenital heart disease have been examined. Of the lesions 56 were cyanotic and 29 acyanotic. The incidence of respiratory infection and of congestive cardiac failure are similar in both groups. The blood $\mathrm{pH}$ is significantly lower in the cyanotic group, and this is due to base depletion. The $\mathrm{PCO}_{2}$ levels are not significantly different in the two groups. In the cyanotic group, in the presence of infection, $\mathrm{PCO}_{2}$ levels and the standard bicarbonate are increased. The differences in $\mathrm{pH}, \mathrm{PCO}_{2}$, and standard bicarbonate between those with failure unaccompanied by infection and those without failure are not significant. The incidence of failure in those with infection is significantly higher.

The importance of arterial $p \mathrm{H}$ in relation to cardiac function is discussed. Hypoxic states are associated with a low arterial $p H$. A $p H$ of less than 7.2 calls for oral or parenteral bicarbonate therapy. An important part of the treatment of "cyanotic attacks" is correction of base depletion. In addition, factors causing hypoventilation, hypovolaemia, and a low cardiac output should be avoided.

We wish to express our thanks to Professor John D. Hay for his guidance and constant encouragement and to $\mathrm{Mr}$. J. C. Kay, of Alder Hey Children's Hospital, Liverpool 12, for his technical help during the period of this study.

\section{REFERENCES}

Darby, T. D., Aldinger, E. E., Gadsden, R. H., and Thrower, W. B. (1960). Circulat. Res., 8, 1242

Friedmann, T. E., Haugen, G. E., and Kmieciak, T. C. (1945). F. biol. Chem., 157, 673.

Gerst, P. H., Fleming, W. H., and Malm, J. R. (1964). Surg. Forum, 15, 242 .

Gootman, N. L., Scarpelli, E. M., and Rudolph, A. M. (1963)

Pediatrics, 31, 251.
Huckabee, W. E. (1958). F. clin. Invest., 37, 244.

Jones, R. S., Kamath, V. R., and Kay, J. C. (1964). f. clin. Path., 17, 564.

Lunholm, L. (1956). Acta physiol. scand., Suppl. No. 133.

Milstein, B. B. (1963). Cardiac Arrest and Resuscitation. Lloyd-Luke, London.

Poole, T. R., and Watts, D. T. (1959). Amer. F. Physiol., 196, 145.

Rudolph, A. M., and Danilowicz, D. (1963). Pediatrics, 32, 141.

Siggard Andersen, O. (1963). Scand. ₹. clin. Lab. Invest., 15, Suppl. No. 70.

Engel, K., Jørgensen, K., and Astrup, P. (1960). Ibid., 12, 172.

— Engel, K., Jørgensen, K., and Astrup, P. (1960). Ibid

Stewart, J. S. S. (1964). Brit. med. 予, 1, 476

Stewart, W. K., and Gillie, H. G. (1962). Lancet, 2, 964.

Sunico, R. M., Harned, H., and Ordway, N. K. (1960). Amer. F. Dis. Child., 100, 531 .

Talner, N. S., Sanyal, S. K., Hallóran, K. H., Gardner, T. H., and Ordway, N. K. (1965). Pediatrics, 35, 20.

Thrower, W. B., Darby, T. D., and Aldinger, E. E. (1961). Arch. Surg.,

82, 56.
Walton, R. P., Richardson, J. A., Walton, R. P., jun., and Thompson, W. L. (1959). Amer. f. Physiol., 197, 223.
.

Yates, F. (1953). Sampling Methods for Censures and Surveys, 2nd ed. Griffin, London. 